\title{
Effects of Feeding Intensity and Ca:P Ratio on Foot Welfare in Blue Foxes (Vulpes lagopus)
}

\author{
Hannu T. Korhonen, Pekka Eskeli, Teijo Lappi, Hanna Huuki, Juhani Sepponen \\ MTT Agrifood Research Finland, Animal Production Research, Kannus, Finland \\ Email: hannu.t.korhonen@mtt.fi
}

Received 25 April 2014; revised 9 June 2014; accepted 25 June 2014

Copyright (C 2014 by authors and Scientific Research Publishing Inc.

This work is licensed under the Creative Commons Attribution International License (CC BY). http://creativecommons.org/licenses/by/4.0/

(c) (i) Open Access

\section{Abstract}

The aim was to clarify effects of ad libitum and restricted feeding with Ca:P ratios on foot welfare in blue foxes. Experiment was started at weaning on August $6^{\text {th }}$ and finished at pelting on November $26^{\text {th }}, 2013$. Treatments were: 1$)$ restricted feeding, Ca:P ratio $\left.1.5: 1 ; 2\right)$ restricted feeding, Ca:P ratio $2.9: 1$; 3) restricted feeding Ca:P ratio control level; 4) ad libitum feeding, Ca:P ratio 1.5:1; 5) ad libitum feeding, Ca:P-ratio 2.9:1; 6) ad libitum feeding Ca:P ratio control level. Body growth variables, feed intake and welfare variables were measured. The behaviour was video recorded. Foreleg carpal joint angle as an indicator of leg weakness and the fox's ability to move were evaluated. During weeks 32 - 35 and 37 - 47 animals from restricted groups ate $60 \%-65 \%$ and $67 \%$ $\mathbf{6 8 \%}$ of the given feed, respectively. Body weight gain was faster in foxes fed ad libitum than with a restricted diet $(\mathrm{P}<0.001)$. At pelting, waistline and neck circumference were significantly $(\mathrm{P}<$ 0.001) larger in ad libitum groups compared to restricted ones. The body condition score was significantly ( $\mathrm{P}<\mathbf{0 . 0 0 1 )}$ larger for ad libitum animals. Body length was greater for ad libitum than for restricted groups $(P<0.05)$. Significant differences were not found in body size variables between Ca:P ratios. During the course of experiment, bending of carpal joints increased in each group $(\mathrm{P}<$ 0.001). Most bended joints were found at final scoring. Significant differences were noted in the angle of joint between ad libitum and restricted groups $(\mathrm{P}<0.05)$. Pronounced difficulties in locomotor activity were not found. Differences between the groups were slight in stick, floorball and capture tests. No pain reaction was evident during sensitivity test. Foot welfare problems were multi-factorial problems.

\section{Keywords}

Farmed Fox, Animal Welfare, Feet Condition, Feeding Level, Animal Production

How to cite this paper: Korhonen, H.T., Eskeli, P., Lappi, T., Huuki, H. and Sepponen, J. (2014) Effects of Feeding Intensity and Ca:P Ratio on Foot Welfare in Blue Foxes (Vulpes lagopus). Open Journal of Animal Sciences, 4, 153-164. 


\section{Introduction}

Body size of farmed blue foxes (Vulpes lagopus) has dramatically increased during the last decades. At pelting, foxes nowadays typically weigh 15 - $20 \mathrm{~kg}$ compared to the time 20 - 30 years ago when foxes pelting weight was clearly less than $10 \mathrm{~kg}$ [1] [2]. Ad libitum feeding and the high amount fat in the diet can partly explain the marked increase of pelting weight. Also effective genetic selection has increased the body size of animals [3]-[5]. Simultaneously, leg weakness and bending of carpal joint have become more common [5]. Obviously, excessive body mass or size combined with such pre-symptoms of osteochondrosis may compromise animal welfare [1] [6] [7].

There is a lack of proper research clarifying reasons causing foot problems [8]. However, it can be assumed to be a sum of various parallel factors. In addition to excessive body mass and size, other influential factors may be the amount of calsium (Ca) and phosphorus (P) and their mutual relationships in the diet [9] [10]. Research on mineral requirement of foxes is unfortunately scarce and was mainly published quite a long time ago. Study by Harris et al. [11] recommends that Ca:P ratio should be 1:1.7. A dietary calcium content below the recommended level was found to cause lameness and bending of leg bones in silver foxes. According to the recommendations based on NRC [12], growing blue foxes minimum requirements of $\mathrm{Ca}$ and $\mathrm{P}$ in the dry matter diets are $0.6 \%$ for each. Valaja et al. [13] reported that ash content of feed $50 \mathrm{~g} / \mathrm{kg}$ dry matter and P content $6 \mathrm{~g} / \mathrm{kg} \mathrm{KA}$ is sufficient to satisfy mineral requirement of growing foxes. A high amount of calcium in the diet may be also problematic. In dogs, overfeeding caused a higher incidence of ossification problems than restricted feeding, and suggested that over supplementation with calcium was a major contributing factor [14]. The upper limit of proper calcium supply in foxes is unknown.

The aim of the present study was to clarify effects of two feeding levels (restricted vs. ad libitum) and the three Ca:P ratios on foot welfare in growing juvenile blue foxes.

\section{Material and Methods}

This study was carried out at MTT Agrifood Research Finland, Kannus, in western Finland. The use of experimental animals was evaluated and approved by the Animal Care Committee of Etelä-Suomen aluehallintovirasto (ESAVI/PH $1231 \mathrm{~A} / 2013)$. The general health of animals was visually checked daily.

\subsection{Experimental Set-up and Animals}

Experimental animals were juvenile male blue foxes born in May 2013. Experiment started at weaning on $\mathrm{Au}-$ gust $6^{\text {th }}$ and finished at pelting on November $26^{\text {th }}$. The foxes were divided into six experimental groups: (1) restricted feeding, Ca:P ratio 1.5:1 (R 1); (2) restricted feeding, Ca:P-ratio 2.9:1 (R 2); (3) restricted feeding Ca:Pratio 2.0:1 control level (R 3); (4) ad libitum feeding, Ca:P ratio 1.5:1 (AL 1); (5) ad libitum feeding, Ca:P-ratio 2.9:1 (AL 2); (6) ad libitum feeding Ca:P-ratio 2.0:1 control level (AL 3). The amount of restricted feeding was set to be $60 \%-70 \%$ of ad libitum level.

Experimental feed was manufactured by Terjärv Frys feed kitchen. Consumption of whole experimental season was made at once, brought to Research Station, and frozen. The amount of feed needed for daily consumption was smelt every day. Composition of diets is given in Table 1 and Table 2 . Animals were fed by hand. Daily feed portions and leftovers were weighed with a Mettler SM 15 balance, accuracy $\pm 1 \mathrm{~g}$. Watering was automatic ad libitum.

Animals were pair-housed in standard wire-mesh cages measuring $105 \mathrm{~cm}$ long $\times 120 \mathrm{~cm}$ wide $\times 70 \mathrm{~cm}$ high. Each cage was furnished with a wire-mesh platform $(105 \mathrm{~cm}$ long $\times 25 \mathrm{~cm}$ wide) located at $23 \mathrm{~cm}$ from the ceiling. Furthermore, a bone $(30 \mathrm{~cm}$ long $\times 7 \mathrm{~cm}$ diameter) as chewing and activity object was placed into cage floor. This furnishment is obligatory for farmed foxes [15].

Animals from same genetic background (same mother) were evenly distributed to each study group. Thus, litter mates were placed equally to groups to homogenize the genetic variability.

\subsection{Body Measures}

Body weights were recorded five times during the study period with a Mettler SM 15 balance, accuracy $\pm 10 \mathrm{~g}$. At pelting, body length, waistline and neck circumference were measured by using tape measure (accuracy \pm 1 $\mathrm{cm})$. 
Table 1. Composition of experimental diets (\%).

\begin{tabular}{cccc}
\hline Ca:P & $1.5: 1$ & $2.9: 1$ & Control 2.0:1 \\
\hline Baltic herring & 25.4 & 28.1 & 31.2 \\
Fish offal & 5.0 & 5.0 & 6.8 \\
Meat and bone meal & 1.0 & 2.1 & 1.3 \\
Slaughterhouse offal; poultry & 5.0 & 17.8 & 2.7 \\
Slaughterhouse offal; bovine, pig & 40.0 & 23.3 & 23.6 \\
Protein admixture, HP 330 & - & - & 0.02 \\
Feathermeal & 0.26 & 0.24 & 2.0 \\
Barley & 3.5 & 3.5 & 3.5 \\
Wheat & 10.0 & 10.0 & 10.0 \\
Fox fat & 3.8 & 3.6 & 5.4 \\
Chalk & 0.3 & - & 2.0 \\
DL-methionine & - & 0.04 & 0.06 \\
Phosphorus acid (75\%) & 0.2 & - & - \\
Water & 5.4 & 6.0 & 11.0 \\
\hline
\end{tabular}

Table 2. Chemical compositions, and calculated contents of metabolizable energy (ME) in the diets. DM = dry matter.

\begin{tabular}{|c|c|c|c|c|}
\hline \multicolumn{2}{|c|}{ Ca:P } & \multirow{2}{*}{$\begin{array}{l}1.5: 1 \\
34.5\end{array}$} & \multirow{2}{*}{$\begin{array}{l}2.9: 1 \\
36.9\end{array}$} & \multirow{2}{*}{$\begin{array}{c}\text { Control 2.0:1 } \\
33.1\end{array}$} \\
\hline DM, \% & & & & \\
\hline In DM (\%), & Ash & 8.8 & 13.4 & 8.1 \\
\hline & Crude protein & 34.5 & 29.4 & 33.0 \\
\hline & Crude fat & 28.2 & 30.9 & 27.8 \\
\hline & Crude carbohydr. & 31.6 & 26.3 & 31.1 \\
\hline \multicolumn{5}{|c|}{ ME (MJ/kg DM) } \\
\hline & Protein & 18.2 & 18.4 & 18.0 \\
\hline & Fat & 27.4 & 25.0 & 28.3 \\
\hline & Carbohydrate & 17.4 & 14.8 & 17.0 \\
\hline
\end{tabular}

The thickness of subcutaneous fat was assessed by a subjective body condition score (BCS) method, which gives an estimate of the degree of fatness independent of the fox's body size [4]. BCS was evaluated for each animal on a scale of $1-5$, where $1=$ very thin and $5=$ extremely fat.

\subsection{Behavioural Tests}

Capture test was made before weighting. Foxes were caught with neck tongs. Capture reaction was classified as confident or fearful [16].

The reactions of the foxes to humans were evaluated by performing a walking test [17] [18]. The test was conducted four times during the study, i.e. on Aug 9, Oct 1, Oct 29 and Nov 15. In the test, researcher walked slowly past the cages and wrote down the behavioural reactions. Behaviours recorded were: sitting, standing, moving, lying, on platform and stereotypy. 
Explorative behaviour was evaluated with a ball test in which a floor ball was placed in the cage. Contact to ball was recorded. If there was no contact within 10 seconds, the test reaction was classified negative.

During the stick test, the researcher was standing in front of the cage and inserted a wooden stick $(150 \mathrm{~cm}$ long, $5 \mathrm{~mm} \varnothing$ ) through the wire-net $25 \mathrm{~cm}$ deep in to the cage. An immediate reaction to the stick stimulus was characterized as follows: (1) escape (fearful); the animal moved away from stimulus; (2) exploration (curious); the animal approached the stick and sniffed and/or bit at the stick; (3) aggressiveness (aggressive); the animal made fast and intense attack at the stick and maintained the bite.

Sensitivity to touch was evaluated four times during the course of study; On Sept 9, Oct 3, Oct 29 and Nov 26. Sensitivity test was performed by touching a footpad sole of fox with a ballpoint pen. Foxes' reaction to touch of an object was immediately recorded. 1 = no reaction, 2 = mild withdrawal, slight pain, 3 = strong withdrawal, marked pain.

\subsection{Behaviour from Video Recordings}

The behaviour was monitored during the experiment. The video recording setup comprised of MIRASYS recorder (V5016H1), monitor (TFTR 17) and 15 cameras (WZI8 PV312-0). The frequency of behaviour was analysed from videotapes using instantaneous sampling at 1 min intervals for one hour (10:00 - 11:00 am) per recording day. Recording days were Aug 13, Sept 4, Sept 23, Oct 1, Oct 8, Oct 15, Oct 22, Oct 29, Nov 5, Nov 12 and Nov 19, respectively.

\subsection{Condition of Feet}

Foreleg carpal joint angle as an indicator of leg weakness and the fox's ability to move about in the cage were evaluated both live and from recordings. Evaluation of carpal tension was based on subjective evaluation forelegs [5] by one evaluator on a scale of $1-5$. In the worst case (score $5=$ very poor), the carpal joint was bended to a $90^{\circ}$ angle compared to normal, only slight angled carpal joint (Score $1=$ excellent). If one of the carpal joints was more bent than the other, the score was based on the worse leg. Ability to move was evaluated as following [19]. If there were no difficulties to move, it was scored to be 0 . The animal was actively moving about in the cage and was able to jump easily on to the platform. Mild difficulties to move were scored as 1 . The fox sometimes moved about in the cage and was somehow capable of jumping on the platform. Marked difficulties to move were scored to be 2 . The fox remained sitting or lying still in the cage, even when shooed off.

\subsection{Evaluation of Fur Quality}

Animals were pelted (Nov 26) according to normal farming practice. Skin grading was performed by Turkistila Luova Oy. Fur characteristics evaluated were fur mass, cover of hair and quality. The scale ranged from 1 (poorest) to 10 (best). Fur defects were also evaluated. Skins were weighed with a Mettler SM 15 balance, accuracy \pm 10 g. Skin length was measured by using a tape measure, accuracy $\pm 1 \mathrm{~cm}$.

\subsection{Statistical Analyses}

The statistical analyses were carried out using SAS/STAT software, Version 9.2 of the SAS System for Windows. Copyright ${ }^{\odot}$ 2009, SAS Institute Inc. SAS and all other SAS Institute Inc. product or service names are registered trademarks or trademarks of SAS Institute Inc [20], Cary, NC, USA.

\subsubsection{Video Recordings}

The original data consisted of eleven recordings (one hour per day, 10:00 - 11:00 am). For the statistical analyses the data was pooled into three periods (period 1: Aug 13, Sept 4, Sept 23, period 2: Oct 1, Oct 8, Oct 15, Oct 22 and period 3: Oct 29, Nov 5, Nov 12 and Nov 19) due to the high variation between recordings within individual animals, especially during the last three or four recordings (period 3).

Repeated measurements of video recordings were analysed using the following linear mixed model:

$$
\mathrm{Y}_{i j k=} \mu+\alpha_{i}+\beta_{j}+\gamma_{k}+(\alpha \beta)_{i j}+(\alpha \gamma)_{i k}+(\beta \gamma)_{j k}+(\alpha \beta \gamma)_{i j k}+\varepsilon_{i j k}
$$

where $\mu$ was the general mean, $\alpha_{i}$ was the fixed effect of feeding intensity (R or AL), $\beta_{j}$ was the fixed effect of 
Ca:P ratio (1.5:1, 2.9:1, control level), $\gamma_{k}$ was the fixed effect of recording period $(1,2,3)$, and $(\alpha \beta)_{i j},(\alpha \gamma)_{i k},(\beta \gamma)_{j k}$ and $(\alpha \beta \gamma)_{i j k}$ were the interactions between fixed effects. $\varepsilon_{i j k}$ was the residual error [21].

Based on the Akaike information criterion (AIC), the covariance structure of the repeated measurements was modelled as compound symmetry (CS), auto-regressive order 1.

(AR1) or unstructured (UN).

\subsubsection{Body Size Variables and Fur Properties}

Measurements of body size variables and fur properties were analysed using the following linear mixed model:

$$
\mathrm{Y}_{i j}=\mu+\alpha_{i}+\beta_{j}+(\alpha \beta)_{i j}+\varepsilon_{i j}
$$

where $\mu$ was the general mean, $\alpha_{i}$ was the fixed effect of feeding intensity (R or AL), $\beta_{j}$ was the fixed effect of Ca:P ratio (1.5:1, 2.9:1, control level) and $(\alpha \beta)_{i j}$, was the interaction between fixed effects. $\varepsilon_{i j}$ was the residual error.

Since the animals were pair-housed mean values of measured parameters of animals within each cage were used in all analyses in all the models. Normality of residuals was checked for each analysis using scatter plots of residuals and fitted values.

\subsubsection{Categorical Variables}

All the categorical variables were analysed using the Fisher's exact test.

\section{Results}

\subsection{Feed Consumption}

Feed consumption in ad libitum groups (AL 1-3) was significantly higher compared to restricted ones (R 1-3) (P $<0.001$; Figure 1). At early phase of the experiment, i.e. on weeks 32 - 35 (Aug 5-Sept 1), animals from restricted groups ate $60 \%$ - 65\% of the amount given to ad libitum animals. During weeks 36-47 (Sept 2-Nov 24) feed consumption of restricted groups averaged 67\% - 68\% of ad libitum level. Animals from R 2 and AL 2 groups had initially slightly poorer appetite compared to other groups. Furthermore, AL 2 animals tended to have poorer feed consumption also on later part of the study, i.e. on weeks 44 - 45 (Oct 28-Nov 10), and week 47 (Nov 18 - 24).

\subsection{Body Size}

Initial body weights of all experimental groups were similar (Table 3). However, already on Sept 9 ad libitum groups (AL 1-3) very significantly differed from restricted feeding groups $(\mathrm{R} 1-3)(\mathrm{P}<0.001)$. This difference between the groups remained until pelting (Nov 26).

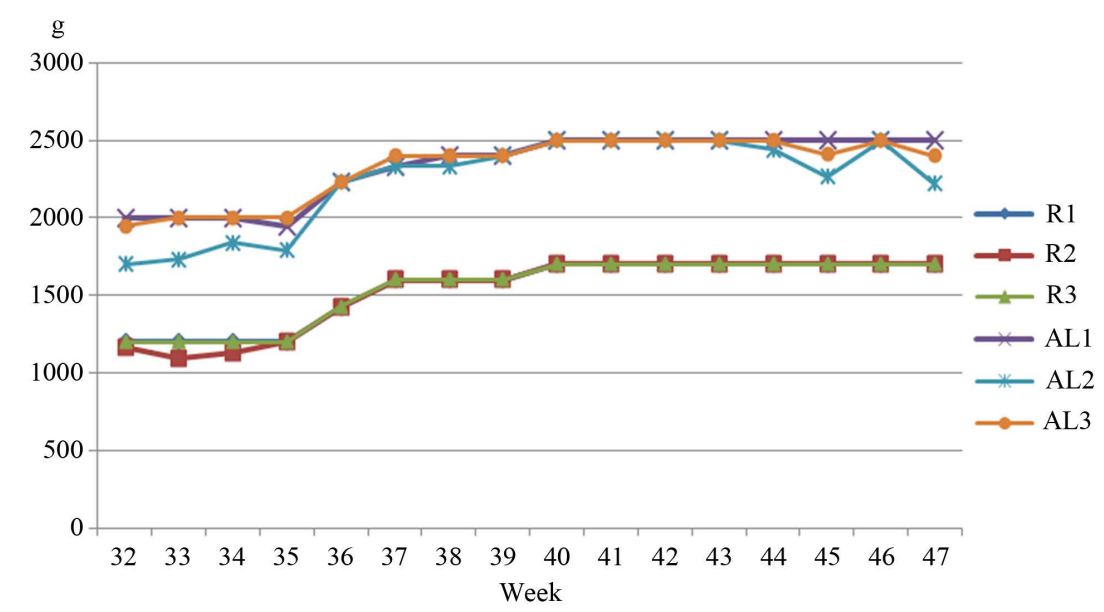

Figure 1. Feed intake of experimental groups (g/animal daily) during study weeks. Week 32: Aug 5 - 11, Week 47: Nov 18 - 24. 
Table 3. Body size variables in exp. groups. Standard deviations (SD) are given in parenthesis. $\mathrm{P}_{1}=$ significance between restricted and ad libitum groups; $\mathrm{P}_{2}=$ significance between Ca:P levels; $\mathrm{P}_{3}=$ Significance between their interactions. ${ }^{*} \mathrm{P}<0.05 ;{ }^{* * *} \mathrm{P}<0.01 ;{ }^{* * *} \mathrm{P}<0.001$. ns $=$ not significant difference. $\mathrm{R} 1$ : restricted feeding, Ca: $\mathrm{P}$ ratio 1.5:1; R2: restricted feeding, Ca:P-ratio 2.9:1; R 3: restricted feeding Ca:P-ratio 2.0:1 control level; AL1: ad libitum feeding, Ca:P ratio 1.5:1; AL2: ad libitum feeding, Ca:P-ratio 2.9:1; AL3: ad libitum feeding Ca:P-ratio 2.0:1 control level.

\begin{tabular}{|c|c|c|c|c|c|c|c|c|c|}
\hline Variable & R 1 & R 2 & R 3 & AL 1 & AL 2 & AL 3 & $\mathrm{P}_{1}$ & $\mathrm{P}_{2}$ & $\mathrm{P}_{3}$ \\
\hline \multicolumn{10}{|c|}{ Body weights, g } \\
\hline \multirow[t]{2}{*}{ Aug 6} & 5105 & 5214 & 5193 & 5106 & 5184 & 5233 & ns & ns & ns \\
\hline & (325) & (229) & (352) & $(462)$ & (488) & (824) & & & \\
\hline \multirow[t]{2}{*}{ Sept 9} & 7556 & 7738 & 7314 & 9224 & 8644 & 8742 & $* * *$ & ns & ns \\
\hline & (541) & (694) & (388) & (712) & (967) & (346) & & & \\
\hline \multirow[t]{2}{*}{ Oct 3} & 9512 & 9822 & 9151 & 12,338 & 11,890 & 11,638 & *** & ns & ns \\
\hline & (995) & (1044) & (893) & $(1142)$ & (1369) & (1199) & & & \\
\hline \multirow[t]{2}{*}{ Oct 29} & 11,230 & 11,822 & 10,822 & 15,556 & 15,118 & 14,456 & $* * *$ & ns & ns \\
\hline & (1391) & (1247) & (1449) & $(1430)$ & (1885) & $(1700)$ & & & \\
\hline \multirow[t]{2}{*}{ Nov 26} & 13,374 & 14,079 & 12,775 & 18,922 & 17,834 & 17,316 & ${ }^{* * *}$ & ns & ns \\
\hline & $(1701)$ & (1247) & (1449) & (1597) & (2398) & (2213) & & & \\
\hline \multicolumn{10}{|c|}{ Body length, cm } \\
\hline \multirow[t]{2}{*}{ Nov 26} & 71.7 & 73.0 & 73.0 & 74.8 & 73.0 & 77.3 & ${ }^{*}$ & ns & $<0.1$ \\
\hline & $(2.1)$ & $(1.7)$ & $(2.1)$ & $(2.1)$ & $(2.8)$ & $(2.8)$ & & & \\
\hline \multicolumn{10}{|c|}{ Waistline, cm } \\
\hline \multirow[t]{2}{*}{ Nov 26} & 65.9 & 66.4 & 64.1 & 80.0 & 78.3 & 77.3 & ${ }^{* * *}$ & ns & ns \\
\hline & (6.1) & $(4.0)$ & $(5.0)$ & (5.1) & $(6.3)$ & (7.9) & & & \\
\hline \multicolumn{10}{|c|}{ Neck circumference, cm } \\
\hline \multirow[t]{2}{*}{ Nov 26} & 35.4 & 36.2 & 35.5 & 41.3 & 41.4 & 41.0 & $* * *$ & ns & ns \\
\hline & $(2.9)$ & $(2.7)$ & $(4.0)$ & $(2.7)$ & (5.4) & $(4.4)$ & & & \\
\hline \multicolumn{10}{|c|}{ Body condition score } \\
\hline \multirow[t]{2}{*}{ Nov 26} & 3.2 & 3.3 & 2.6 & 4.9 & 4.8 & 4.6 & ${ }^{* * *}$ & $*$ & ns \\
\hline & $(0.8)$ & $(0.7)$ & $(0.5)$ & $(0.3)$ & $(0.4)$ & $(0.7)$ & & & \\
\hline
\end{tabular}

Waistline and neck circumference were significantly larger in ad libitum groups compared to restricted ones (Table 3). Also body condition score (BSC) was significantly larger for ad libitum animals. Significant differences were not found in body length at pelting. However, there was a clear tendency $(\mathrm{P}<0.08)$ that the foxes in ad libitum group were longer than the ones in restricted diet groups.

\subsection{Bending of Feet}

The scores for the angle of joints in each group are presented in Table 4. In the beginning of experiment the condition of animals' joints was found to be either good (score 2) or excellent (score 1). Only few animals were classified to score 3 (sufficient). Initially, there were no significant differences in level of bent joints between study groups. During the course of experiment bending of joints increased in each group. This increase between initial and final scoring was significant $(\mathrm{P}<0.001)$. 
Table 4. Bending of feet expressed as percentage of animals having score from 1 to 4.

\begin{tabular}{|c|c|c|c|c|c|c|c|}
\hline Date & Score & R 1 & R 2 & R 3 & AL 1 & AL 2 & AL 3 \\
\hline \multirow[t]{4}{*}{ Aug 6} & 1 & 0 & 10 & 0 & 0 & 0 & 10 \\
\hline & 2 & 80 & 90 & 80 & 90 & 100 & 80 \\
\hline & 3 & 20 & 0 & 20 & 10 & 0 & 10 \\
\hline & 4 & 0 & 0 & 0 & 0 & 0 & 0 \\
\hline \multirow[t]{4}{*}{ Sept 6} & 1 & 0 & 10 & 0 & 0 & 0 & 10 \\
\hline & 2 & 70 & 70 & 80 & 70 & 80 & 70 \\
\hline & 3 & 30 & 20 & 20 & 30 & 20 & 20 \\
\hline & 4 & 0 & 0 & 0 & 0 & 0 & 0 \\
\hline \multirow[t]{4}{*}{ Oct 10} & 1 & 0 & 0 & 0 & 0 & 0 & 0 \\
\hline & 2 & 40 & 60 & 60 & 30 & 50 & 33.3 \\
\hline & 3 & 60 & 40 & 40 & 70 & 50 & 66.7 \\
\hline & 4 & 0 & 0 & 0 & 0 & 0 & 0 \\
\hline \multirow[t]{4}{*}{ Oct 29} & 1 & 0 & 0 & 0 & 0 & 0 & 0 \\
\hline & 2 & 20 & 10 & 20 & 0 & 11.1 & 33.3 \\
\hline & 3 & 20 & 90 & 30 & 40 & 33.3 & 33.3 \\
\hline & 4 & 60 & 0 & 50 & 60 & 55.6 & 33.3 \\
\hline \multirow[t]{4}{*}{ Nov 18} & 1 & 0 & 0 & 0 & 0 & 0 & 0 \\
\hline & 2 & 20 & 10 & 20 & 0 & 0 & 11.1 \\
\hline & 3 & 20 & 80 & 10 & 20 & 44.4 & 55.6 \\
\hline & 4 & 60 & 10 & 70 & 80 & 55.6 & 33.3 \\
\hline
\end{tabular}

Most bended joints were found during the last scoring on Nov 18. Only significant differences $(P=0.008)$ here were found between R 1, R 2 and R 3 groups. Percentage of animals having score 4 (poor) was 60, 10 and $70 \%$, respectively. Furthermore, when Nov 18 data from ad libitum and restricted feeding groups was pooled together, it was found that $\mathrm{Ca}: \mathrm{P}$ level almost significantly $(\mathrm{P}=0.057)$ explained amount bending of feet. During Nov 18, the percentage of animals having score 4 (= poor) in groups with Ca:P ratios of 1.5:1, 2.9:1 and control were $70 \%$, $31.6 \%$ and $52.6 \%$, respectively.

Significant differences were found in joint bending between ad libitum and restricted groups. Neither significant differences between ad libitum groups, nor differences when Nov 18 data from Ca:P levels were pooled together was found.

\subsection{Ability to Move}

Essential difficulties to move were not found. Thus, animals having a score 2 or 3 for the level of moving was not found until November. However, slight difficulties to move were more common in ad libitum fed animals compared to ones in restricted feeding group. Percentage of animals that scored 1 in groups R $1, \mathrm{R} 2, \mathrm{R} 3, \mathrm{AL} 1$, AL 2 and AL 3 were 10, 10, 0, 90, 56 44, respectively $(\mathrm{P}<0.001)$. Significant differences were not found between AL groups in ability to move $(\mathrm{P}=0.121)$.

\subsection{Behavioural Reactions}

Only few differences were found in reactions for behavioural test between the study groups (Table 5). No differences at all were found in stick and floor ball test. In the capture test, however, significant difference was ob- 
Table 5. Number of confident foxes at capture and stick tests, and explorative animals at floorball test. $\mathrm{P}=$ significance between all groups. ${ }^{*} \mathrm{P}<0.05 ;{ }^{* *} \mathrm{P}<0.01$. ns $=$ not significant difference.

\begin{tabular}{|c|c|c|c|c|c|c|c|}
\hline Variable/Date & R 1 & R 2 & R 3 & AL 1 & AL 2 & AL 3 & $\mathrm{P}$ \\
\hline \multicolumn{8}{|c|}{ Capture test, confident } \\
\hline Aug 6 & 9 & 7 & 10 & 7 & 8 & 9 & ns \\
\hline Sept 9 & 5 & 4 & 5 & 8 & 10 & 5 & $*$ \\
\hline Oct 3 & 8 & 8 & 5 & 9 & 10 & 8 & ns \\
\hline Oct 29 & 9 & 3 & 4 & 4 & 6 & 8 & * \\
\hline Nov 26 & 6 & 8 & 7 & 8 & 8 & 6 & ns \\
\hline \multicolumn{8}{|c|}{ Stick test, confident } \\
\hline Sept 6 & 1 & 0 & 1 & 0 & 1 & 2 & ns \\
\hline Sept 30 & 0 & 1 & 1 & 0 & 2 & 2 & ns \\
\hline Nov 14 & 0 & 0 & 0 & 0 & 0 & 0 & ns \\
\hline \multicolumn{8}{|c|}{ Floorball test, explorative } \\
\hline Sept 6 & 3 & 1 & 4 & 3 & 2 & 2 & ns \\
\hline Sept 30 & 2 & 1 & 1 & 3 & 4 & 1 & ns \\
\hline Nov 14 & 3 & 1 & 4 & 3 & 2 & 2 & ns \\
\hline
\end{tabular}

served in Sept 9 and Oct 29. These differences were not systematic, so, any clear tendency for or against certain group cannot be given.

No withdrawal or pain reaction was found when testing sensitivity to touch in foxes. All footpads were healthy in appearance.

Walking test results are shown in Table 6. Only few differences were observed between the study groups. Ad libitum fed foxes were found to sit significantly more than restrictedly fed foxes on Oct $29(\mathrm{P}<0.05)$. Furthermore, a tendency was found that sitting was more common in ad libitum fed animals on Nov 15. Stereotypic behaviour was not observed during any walking test session.

\subsection{Video Analyses}

Data from video recordings are presented in Figure 2. Activity of foxes was highest in August and declined towards pelting at November $(\mathrm{P}<0.001)$. Activity of foxes was same order of magnitude in all experimental groups. The amount of sitting was lowest in early August and increased gradually towards pelting $(\mathrm{P}<0.001)$. Sitting increased more in the ad libitum fed groups than in the restrictedly fed groups $(\mathrm{P}<0.05)$.

The amount of standing increased more in the restrictedly fed groups $(\mathrm{P}<0.05)$. The amount of lying increased in the ad libitum fed groups while it remained constant in the restricted groups $(\mathrm{P}<0.001)$. Platform use tended to be lowest in ad libitum fed groups. This tendency was more clear in late autumn.

\subsection{Fur Properties}

Clear differences were found in fur properties between the experimental groups (Table 7). Skin length and weight was greater in foxes fed ad libitum compared to restrictedly fed ones. Furthermore, fur mass and fur quality were better in ad libitum fed animals. Ca:P levels did not affect skin weight, length or fur mass of animals. The cover of hair and fur quality were poorest in animals fed 2.9:1 diet.

\section{Discussion}

Genetic background of animals was homogenized. This allowed us to compare more accurately effects of feeding intensity and Ca:P diets on foot welfare. As our growing data showed we successfully produced foxes of 

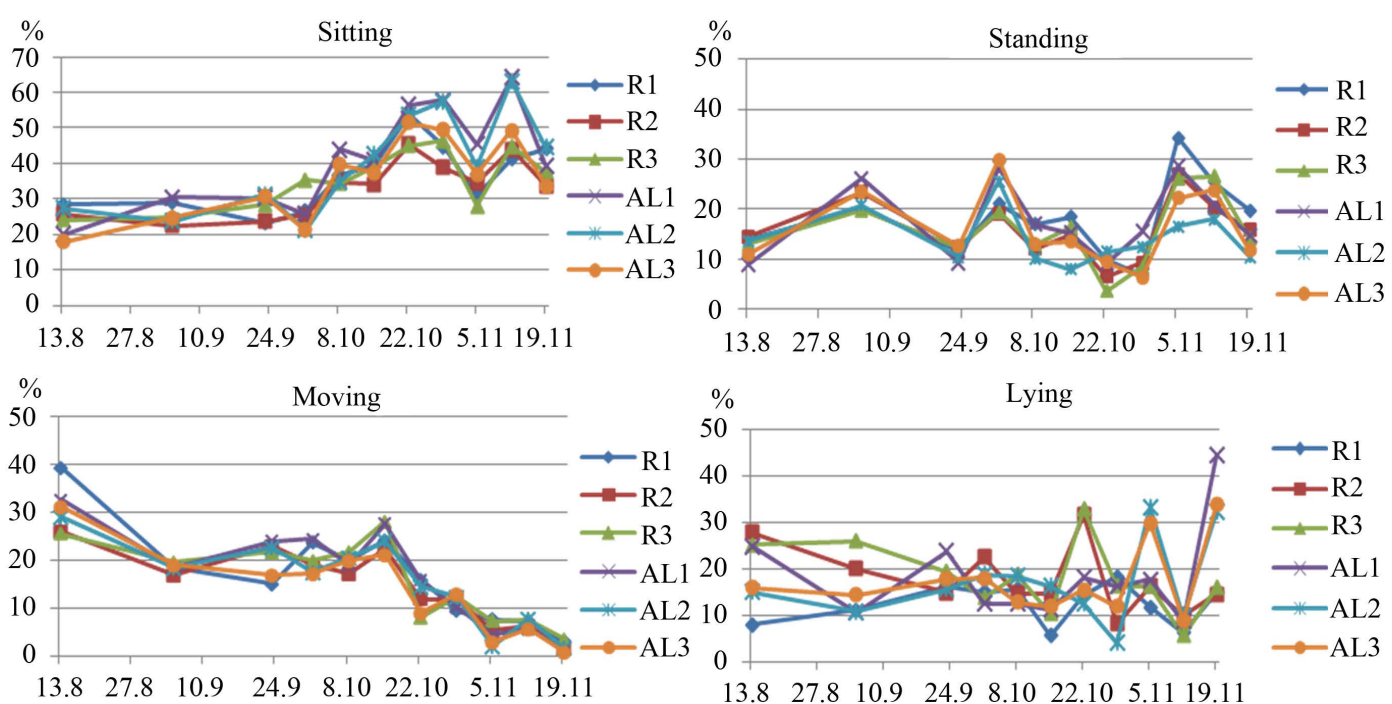

Figure 2. Percentage of sitting, standing, moving and lying from total daily time analysed. Notice the different scaling of $\mathrm{y}$-axis in the graph illustrating the sitting behaviour. Video recording dates are given in $\mathrm{x}$-axis.

Table 6. Behavioural reactions during walking test. Data are given as number of animals performing the behaviour. $\mathrm{P}=$ significance between all groups. ${ }^{*} \mathrm{P}<0.05$. $\mathrm{ns}=$ not significant difference.

\begin{tabular}{|c|c|c|c|c|c|c|c|c|}
\hline Date & Variable & R 1 & R 2 & R 3 & AL 1 & AL 2 & AL 3 & $P$ \\
\hline \multirow[t]{5}{*}{ Aug 9} & Sitting & 5 & 6 & 4 & 3 & 4 & 5 & \\
\hline & Standing & 0 & 0 & 1 & 0 & 0 & 1 & \\
\hline & Moving & 2 & 2 & 0 & 4 & 0 & 1 & ns \\
\hline & Lying & 2 & 0 & 1 & 0 & 3 & 0 & \\
\hline & On platform & 1 & 2 & 4 & 3 & 3 & 2 & \\
\hline \multirow[t]{5}{*}{ Oct 1} & Sitting & 1 & 4 & 2 & 2 & 5 & 4 & \\
\hline & Standing & 4 & 0 & 2 & 5 & 2 & 4 & \\
\hline & Moving & 3 & 2 & 3 & 2 & 1 & 0 & ns \\
\hline & Lying & 0 & 0 & 0 & 0 & 0 & 0 & \\
\hline & On platform & 2 & 4 & 3 & 1 & 2 & 1 & \\
\hline \multirow[t]{5}{*}{ Oct 29} & Sitting & 2 & 3 & 0 & 8 & 5 & 2 & \\
\hline & Standing & 2 & 2 & 2 & 1 & 3 & 1 & \\
\hline & Moving & 1 & 1 & 4 & 0 & 1 & 2 & * \\
\hline & Lying & 2 & 3 & 1 & 0 & 0 & 4 & \\
\hline & On platform & 3 & 1 & 3 & 1 & 0 & 0 & \\
\hline \multirow[t]{5}{*}{ Nov 15} & Sitting & 2 & 4 & 1 & 5 & 5 & 6 & \\
\hline & Standing & 3 & 2 & 4 & 5 & 4 & 2 & \\
\hline & Moving & 1 & 0 & 2 & 0 & 0 & 0 & 0.06 \\
\hline & Lying & 3 & 1 & 0 & 0 & 0 & 1 & \\
\hline & On platform & 1 & 3 & 3 & 0 & 0 & 0 & \\
\hline
\end{tabular}


Table 7. Comparison of fur properties. Standard deviations (SD) are given in parenthesis. $\mathrm{P}_{1}=$ significance between restricted and ad libitum groups; $\mathrm{P}_{2}=$ significance between $\mathrm{Ca}: \mathrm{P}$ levels; $\mathrm{P}_{3}=$ Significance between their interactions. ${ }^{*} \mathrm{P}<0.05 ;{ }^{* *} \mathrm{P}<0.01 ;{ }^{* * *} \mathrm{P}<0.001$. ns = not significant difference.

\begin{tabular}{cccccccccc}
\hline Variable & R1 & R2 & R3 & AL1 & AL2 & AL3 & $\mathrm{P}_{1}$ & $\mathrm{P}_{2}$ & $\mathrm{P}_{3}$ \\
\hline Skin weight, g & 817.5 & 825.5 & 831.0 & 1060.5 & 900.6 & 935.0 & $* * *$ & $\mathrm{~ns}$ & 0.06 \\
& $(104.9)$ & $(85.4)$ & $(96.6)$ & $(121.1)$ & $(134.7)$ & $(145.5)$ & & & \\
Skin length, cm & 130.9 & 130.7 & 128.1 & 141.7 & 134.8 & 136.7 & $* * *$ & $\mathrm{~ns}$ & $\mathrm{~ns}$ \\
& $(5.7)$ & $(7.7)$ & $(5.9)$ & $(6.4)$ & $(7.8)$ & $(8.1)$ & & & \\
Fur mass & 6.1 & 6.1 & 6.3 & 7.8 & 6.7 & 7.7 & $* *$ & $\mathrm{~ns}$ & $\mathrm{~ns}$ \\
Cover of hair & $(1.1)$ & $(1.2)$ & $(1.5)$ & $(1.1)$ & $(1.3)$ & $(2.0)$ & & & \\
Quality & 6.5 & 5.5 & 6.2 & 6.8 & 5.9 & 7.2 & 0.07 & $*$ & $\mathrm{~ns}$ \\
& $(1.2)$ & $(1.0)$ & $(1.9)$ & $(1.5)$ & $(0.9)$ & $(1.0)$ & & & \\
& 6.7 & 6.0 & 6.2 & 7.5 & 6.1 & 7.6 & $*$ & $*$ & $\mathrm{~ns}$ \\
\hline
\end{tabular}

two different body weight lines. Growth curves of ad libitum fed animals very significantly differed from restricted ones. Final body weights of ad libitum groups averaged over $4.5 \mathrm{~kg}$ heavier compared to restricted groups. Also their final body length, waistline and neck circumferences were significantly larger. Significant difference was also seen in body condition score (BSC) between feeding regimens. Furthermore, there were significant differences in weight curves between feeding intensity groups. This allowed us to further compare the effects of Ca:P ratio on foot welfare. Our experimental set-up also proved the possibility to evaluate the results as a combination of feeding intensity and Ca:P ratio.

"Ability to move" is one of animal-based parameters developed for on-farm welfare assessment protocols in foxes [19]. It is based on 4-level scaling and has previously proven to be reliable. For present study we selected the fore mentioned scoring system, although other scoring mechanisms have been developed. Kempe et al. [4] have also described a corresponding scoring for evaluation of ability to move. Actually their scoring system is similar to the one used in the present study, but their scale is reversed, i.e. highest number is the best. Our results showed that number of foxes marked to show difficulties to move or not moving at all was zero. Hence, our experimental set-up produced only foxes either having no difficulties to move or foxes having only mild moving difficulties. However results showed significant differences in ability to move between the two groups with different feeding intensities. Number of foxes having mild difficulties was greater in animals fed ad libitum. While genetic background of animals was similar, we can conclude that intensive feeding can result in some moving difficulties in foxes. These moving difficulties, however, were not very serious. Our results did not show any indication that Ca:P level could affect moving ability. It looks that difficulties to move are more due to the excessive body mass than to composition of diet.

Bending of feet was evaluated here using a 5-point scale [4] [19]. At the beginning of experimental study there were no differences in feet bending between groups. This was due to homogeneity of genetic background of animal material. Furthermore, there were initially only few animals having excellent feed condition i.e. no bending at all. Most foxes were initially scored to have slight bending. So, our genetic material was such that almost all foxes already initially had slight tendency for feet bending. This is rather typical for foxes on commercial farms nowadays. It is difficult to find foxes having totally healthy feet conditions. Our results showed that the amount of foxes having greater feet bending increased during the course of study. Highest bending scoring was found at final evaluation on Nov 18. However, highest bending scoring, i.e. scale point 5 was not found in any of the animals.

Feeding intensity had no effect on bending of feet. This clearly shows that difficulties to move observed in ad libitum fed animals are not due to bending of feet but due to excessive body mass. Simply, obese animals have problems to move because of excessive body mass and fat. This kind of indication was evident already in our previous experiments [17] [18]. 
Our feed intake data revealed that foxes (AL 2, R 2) fed Ca:P ratio 2.9:1 had initially and also in the later part of study poorer appetite than in other groups. Palatability of this ratio feed was therefore not best possible. Furthermore, composition of diet showed marked tendency to produce bending of joints. Most bent joins were found in Ca:P ratio 2.9:1 and, correspondingly, least bent joints in 1.5:1 ratio. So, it looks that the high amount of calcium may not have any preventing influence on bending. However, the number of animals per group in our study was only 10 , so, the result requires further clarification with larger animal numbers.

It is typical that foxes' activity declines towards autumn and winter [17] [18] [22]. During pelting time their moving level is generally low. Our video recordings revealed that locomotor activity of foxes initially was similar. Locomotor activity also declined rather similarly in all groups during the course of experiment. Body weight of groups did not essentially affect the amount of locomotor activity. Opposite to locomotion, the amount of sitting in all groups significantly increased towards pelting time. Thus, the approach of winter disabled the farmed blue foxes. This seems not to be solely dependent on feeding intensity. Video recordings did not reveal marked difference in sitting and standing between groups. Only walking test in Nov 15 revealed a tendency that foxes fed ad libitum were sitting more in approach of man than the restrictedly fed foxes.

The reason why farmers typically produce large, obese foxes is their expectation of bigger size skins and better fur quality. The present results confirm this concept. Ad libitum fed foxes had longer skin and heavier skin weight. Also their fur quality was better than in foxes fed restricted amount.

According to present results foot welfare problems are due to multi-factorial causes. Particularly bending of joints is not only due to body mass or feeding alone. It quite like depends also on genetic factors, too. Therefore, it is import that proper selection is used for breeding animals. Vixens having tendency for pronounced feet bending should be avoided for breeding purposes. In addition, excessive body mass to a certain extent enhances the bending of joints if animals have a genetic tendency for that. Our results also tempt us to conclude that Ca:P ratio in the feet may partly be involved in bending problematic. However, further research is needed to understand this complex, multi-factorial problem. Ability to move not necessarily has nothing to do with bending of feet. It looks more to be due to too obese body mass. Furthermore, sensitivity test did not reveal any differences between the animals. This means that footpad sole of all animals was in normal conditions. Difficulties to move or bending of joints do not seem to be related to footpad conditions.

\section{Conclusion}

Present results showed that ad libitum feeding produced obese foxes with high amount of subcutaneous fat around waist and neck. This was also seen as a high body condition score (BSC) index. Intensive feeding caused some difficulties to move particularly in the approach of winter season. Bending of feet seems to be a multi-factorial problem.

\section{Acknowledgements}

This study was financially supported by the Finnish Fur Breeders’ Association.

\section{References}

[1] Korhonen, H.T., Happo, M., Rekilä, T., Valaja, J. and Pölönen, I. (2005) Effects of Diet Calcium: Phosphorous Ratio and Metabolizable Energy Content on Development of Osteochondrosis, Foot Bending and Performance in Blue Foxes. Animal Science, 80, 325-331. http://dx.doi.org/10.1079/ASC40620325

[2] Rimeslåtten, H. (1976) Experiments in Feeding Different Levels of Protein, Fat and Carbohydrates to Blue Foxes. The First International Scientific Congress in Fur Animal Production, Helsinki, 27-29 April 1976, 21.

[3] Kempe, R., Stranden, I., Koivula, M., Rekilä, T., Koskinen, N. and Mäntysaari, E. (2008) Genetic Parameters of Feed Efficiency and Its Relationships with Feed Intake, Daily Gain and Animal Size Traits in Finnish Blue Fox (Alopex lagopus). Scientifur, 32, 47-52.

[4] Kempe, R., Koskinen, N., Peuta, J., Koivula, M. and Stranden, I. (2009) Body Condition Scoring Method for Blue Fox (Alopex lagopus). Acta Agriculturae Scandinavica, 59, 85-92. http://dx.doi.org/10.1080/09064700903045341

[5] Kempe, R., Koskinen, N., Mäntysaari, E. and Stranden, I. (2010) The Genetics of Body Condition and Leg Weakness in the Blue Fox (Alopex lagopus). Acta Agriculturae Scandinavica, 60, 141-150. http://dx.doi.org/10.1080/09064702.2010.515241

[6] Smith, C.W. (1991) Osteochondrosis in the Dog—Diagnosis, Treatment, and Prognosis. Canine Practice, 16, 15-22. 
[7] Korhonen, H.T., Niemelä, P. and Jauhiainen, L. (2001) Effect of Space and Floor Material on the Behaviour of Farmed Blue Foxes. Canadian Journal of Animal Science, 81, 189-197. http://dx.doi.org/10.4141/A00-093

[8] Tauson, A.-H., Lindal Olafsson, B., Elnif, J., Treuthardt, J. and Ahlstrøm, Ø. (1992) Minkens och rävens mineralförsörjning. NJF-utredning/rapport nr 79, Jordbrugsforlaget, Copenhagen, 104.

[9] Tryfonidou, M.A., Holl, M.S., Vastenburg, M., Oosterlaken-Dijksterhuis, M.A., Birkenhäger-Frenkel, D.H., van den Brom, W.E. and Hazewinkel, H.A.W. (2003) Hormonal Regulation of Calcium Homeostasis in Two Breeds of Dogs during Growth at Different Rates. Journal of Animal Science, 81, 1568-1580.

[10] Dobenecker, B. (2011) Factors That Modify the Effect of Excess Calcium on Skeletal Development in Puppies. British Journal of Nutrition, 106, 142-145. http://dx.doi.org/10.1017/S0007114511002959

[11] Harris, L.E., Basset, C.F. and Wilke, C.F. (1951) Effects of Various Levels of Calcium, Phosphorus and Vitamin D Intake on Bone Growth. I. Foxes. Journal of Nutrition, 43, 153.

[12] NRC (1982) Nutrient Requirements of Mink and Foxes. National Research Council, National Academy Press, Washington DC.

[13] Valaja, J., Pölönen, I., Rekilä, T., Nenonen, N. and Jalava, T. (2002) Calcium and Phosphorus Nutrition of Blue Foxes. NJF-Seminar No. 347, Vuokatti, Finland. 6.

[14] Hedhammer, A., Wu, F., Krook, L., Schryver, H.F., DelaHunta, A., Whalen, J.P., Kallfelz, F.A., Nunex, E.A., Hintz, H.F., Sheffy, B.E. and Ryan, G.D. (1974) Overnutrition and Skeletal Disease. An Experimental Study in Growing Great Dane Dogs. Cornell Veterinary, 64, 5.

[15] Koistinen, T. and Korhonen, H.T. (2013) Complex Housing Environment for Farmed Blue Foxes (Vulpes lagopus): Use of Various Resources. Animal, 7, 1354-1361. http://dx.doi.org/10.1017/S1751731113000402

[16] Korhonen, H.T. and Huuki, H. (2011) Digging and Its Welfare Implications for Farmed Blue Fox. Annals of Animal Science, 11, 293-305.

[17] Korhonen, H.T., Jauhiainen, L., Niemelä, P., Harri, M. and Sauna-aho, R. (2001) Physiological and Behavioural Responses in Blue Foxes (Alopex lagopus): Comparisons between Space Quantity and Floor Material. Animal Science, 72, 375-387.

[18] Korhonen, H.T., Jauhiainen, L. and Niemelä, P. (2001) Effect of Space Allowance and Earthen Flooring on Behaviour of Farmed Blue Foxes. Acta ethologica, 4, 11-21. http://dx.doi.org/10.1007/s102110100046

[19] Mononen, J., Moller, S.H., Hansen, S.W., Hovland, A.L., Koistinen, T., Lidfors, L., Malmkvist, J., Vinke, C. and Ahola, L. (2012) The Development of On-Farm Welfare Assessment Protocols for Foxes and Mink: The WelFur Project. Animal Welfare, 21, 363-371. http://dx.doi.org/10.7120/09627286.21.3.363

[20] SAS Institute Inc. (2009) SAS/STAT ${ }^{\circledR} 9.2$ User’s Guide. Cary, NC: SAS Insitute Inc., 633.

[21] Littell, R.C., Milliken, G.A., Stroup, W.W. and Wolfinger, R.D. (1996) SAs System for Mixed Models. Cary, NC. SAS Institute Inc., 633.

[22] Korhonen, H. (1988) Seasonal Changes in Activity and Behavioural Patterns of Farm-Raised Foxes (Alopex lagopus). Scientifur, 12, 27-37. 
Scientific Research Publishing (SCIRP) is one of the largest Open Access journal publishers. It is currently publishing more than 200 open access, online, peer-reviewed journals covering a wide range of academic disciplines. SCIRP serves the worldwide academic communities and contributes to the progress and application of science with its publication.

Other selected journals from SCIRP are listed as below. Submit your manuscript to us via either submit@scirp.org or Online Submission Portal.
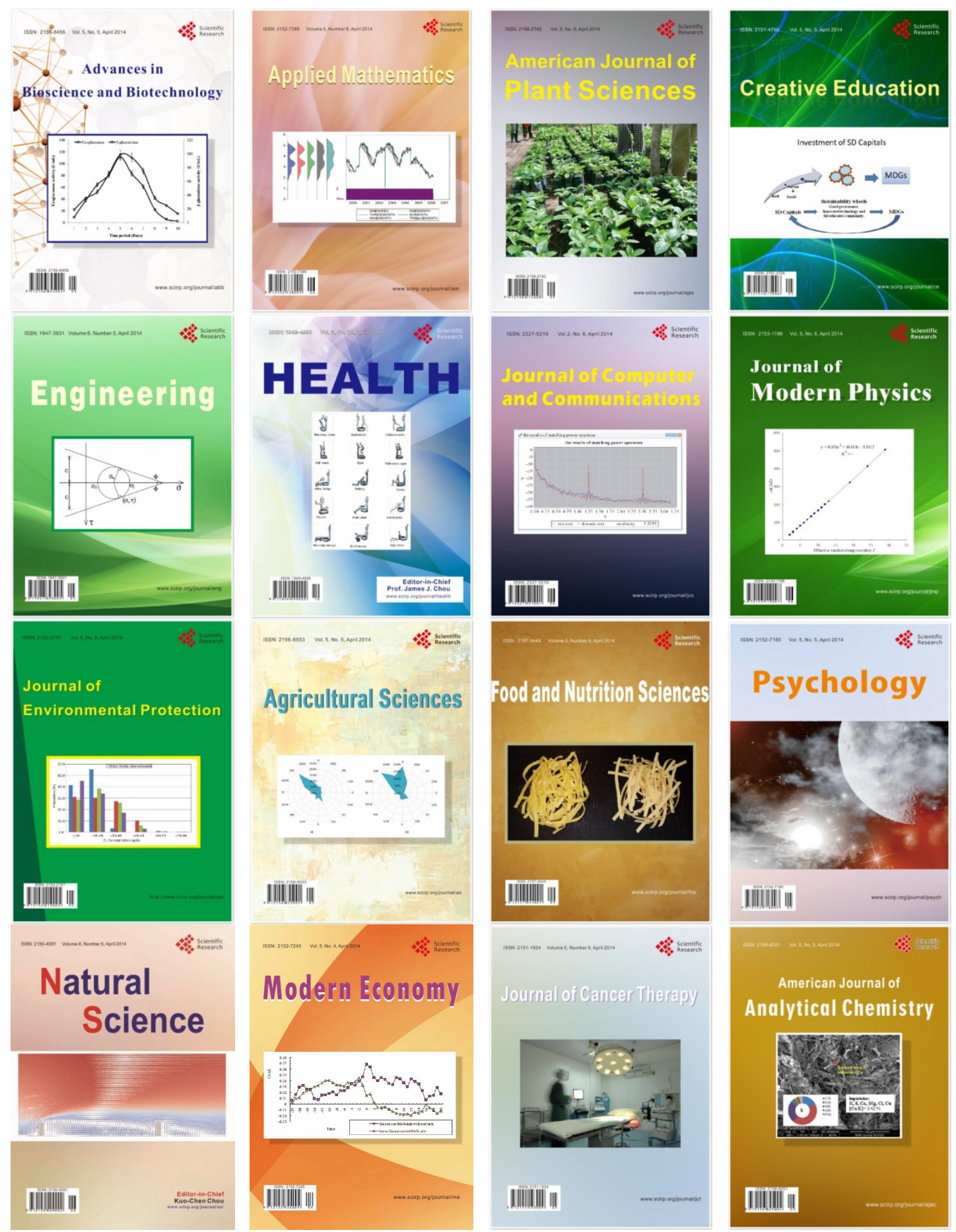